\title{
Penerapan Biomekanika pada Alat Peraga Push Up
}

\author{
Kasyfi Rifqi Mouromadhoni ${ }^{1 *}$, Heru Kuswanto ${ }^{2}$ \\ *e-mail: 7117000020.2017@ student.uny.ac.id \\ ${ }^{1}$ Program Studi Pendidikan Sains, Program Pascasarjana Universitas Negeri Yogyakarta \\ ${ }^{2}$ Program Studi Pendidikan Fisika, Program Pascasarjana Universitas Negeri Yogyakarta
}

\begin{abstract}
Biomechanics is part of a scientific discipline that applies basic mechanical principles to explain the performance system in the human body (living things). One application in the human body is when doing push ups. Push up props are made to find out the relationship between arm length, mass, and angle to the force and torque. After the tool is assembled, the tool is experimented with mass manipulation variables $125 \mathrm{~g}$; $290 \mathrm{~g} ; 515 \mathrm{~g}$ and body length 20;40; $60 \mathrm{~cm}$. Based on the experimental results that the greater the arm's length, the greater the force and torque. The greater the mass of the object, the greater the force.
\end{abstract}

Keywords: biomechanics, push-ups, torque, newton

\begin{abstract}
ABSTRAK
Biomekanika merupakan bagian dari disiplin ilmu yang menerapkan prinsip dasar mekanik untuk menjelaskan sistem kinerja pada tubuh manusia (makhluk hidup). Salah satu penerapannya dalam tubuh manusia adalah ketika melakukan push up. Dibuatlah alat peraga push up untuk mengetahui hubungan antara panjang lengan, massa, dan sudut terhadap besar gaya dan torsi. Setelah alat terangkai, alat dieksperimenkan dengan variable manipulasi massa $125 \mathrm{~g} ; 290 \mathrm{~g} ; 515 \mathrm{~g}$ dan panjang lengan badan 20;40;60 cm. Berdasarkan hasil eksperimen bahwa semakin besar panjang lengan badan maka semakin besar pula gaya dan torsi. Semakin besar massa benda maka semakin besar pula gaya.
\end{abstract}

Kata Kunci: biomekanik, push-up, torsi, newton

\section{PENDAHULUAN (12Pt)}

Biomekanik merupakan bagian dari disiplin ilmu yang meminjam prinsip dasar mekanik untuk menjelaskan sistem kinerja pada tubuh manusia (makhluk hidup). Dalam biomekanika, prinsipprinsip mekanika dipakai dalam penyusunan konsep, analisis, desain, dan pengembangan peralatan yang merefleksikan sistem kinerja otot pada tubuh manusia. Pendekatan biomekanik dapat dilihat pada penerapan biomekanik olahraga atau latihan kebugaran tubuh seperti push-up. Biomekanik di bidang olahraga dan latihan memerlukan pendekatan penelitian berdasarkan campuran eksperimen dan pemodelan teoritis (Payton dan Bartlett, 2008). Secara ekstensif olahraga push-up digunakan dalam pengujian dan pelatihan kekuatan dari beragam individu, seperti atlet dan pemanasan pada anak-anak (Suprak, Dawes, dan Stephenson, 2011).

Push-up menjadi bagian dari olaraga yang tidak membutuhkan mekanisme dan peralatan yang rumit dalam praktisnya. Namun secara 
prosedural perlu dimegerti, olaraga pushup yang dilakukan tidak sesuai dengan mekanisme akan memicu cidera ringan maupun cidera berat. Contreras, et. el (2012), pola pembentukan otot dan tekanan sendi yang dapat memicu pontensi cidera dipengaruhi variasi yang melibatkan perubahan posisi kaki dan tangan. Konsep dasar biomekanik pada olahraga push-up yaitu menghasilkan kesetimbangan pada kekakuan tulang punggung, panggul, pinggang, dan persendian lutut pada satu garis lurus.

Mengaplikasikan biomekanik pada olahraga push-up untuk menghasilkan instrument praktikum sederhana masih tergolong baru. Youdas, et. el (2010) modifikasi peralatan pada olahraga push-up hanya pada pegangan yang dirancang bergerak (berputar) dapat mengurangi ketengan otot dan cidera serta memperbaiki kesetimbangan, fleksibilitas, dan kekuatan saat melakukan push-up. Meskipun, olahraga push-up merupakan latihan penguatan dasar, ketersediaan informasi mengenai pengaplikasian pada instrument praktikum masih terbilang kurang. Aplikasi konsep sederhana pada push-up dapat direfleksikan pada tuas (pengungkit). USAID PRIORITAS, (2017) aktivitas manusia dalam proses push-up dapat diaplikasikan pada penerapan pesawat sederhana pada tuas jenis ke dua. Disamping itu, pengukuran variabel lain yang dapat dilakukan pada aktivitas push-up mengukur tegangan geser pada siku, gaya reaksi tanah yang ditimbulkan terhadap gaya tekan tubuh.

Ketika sedang push up ada berbagai hukum fisika yang bekerja. Yang pertama adalah Hukum III Newton yang berbunyi ketika dua benda berinteraksi, gaya pada kedua benda yang berasal dari satu sama lain selalu selalu sama magnitudonya dan berlawanan arah (Halliday,2005). Kemudian menurut Hewitt (2007) bahwa kita bisa memanggil satu kekuatan gaya tindakan, dan kita bisa memanggil yang lain kekuatan reaksi. Yang penting adalah bahwa mereka adalah bagian yang sama dari satu interaksi dan bahwa kekuatan tidak ada tanpa yang lain. Gaya aksi dan reaksi sama dalam kekuatan dan berlawanan arah. Mereka terjadi berpasangan, dan mereka membentuk satu interaksi antara dua hal.

Berdasarkan paparan diatas adalah gaya pertama disebut gaya aksi dan gaya yang lain disebut gaya reaksi. Gaya aksi sama besarnya dengan gaya reaksi serta memiliki arah yang berlawanan. Gayagaya tersebut terjadi secara berpasangan dan membuat interaksi tunggal diantara dua benda dan tidak akan ada satu gaya yang muncul jika tidak ada gaya lainya. Sehingga menurut hukum ketiga Newton, lantai memberikan reaksi ke atas dengan gaya yang sama, misalnya F. Gaya reaksi ini bekerja pada orang tersebut . sehingga dapat dirumuskan debagai berikut:

$$
\mathrm{F}_{\mathrm{aksi}}=-\mathrm{F}_{\text {reaksi }}
$$

Dalam gerakan push-up berlaku juga kesetimbangan gaya dan torka. Menurut Halliday (2005), persyaratan agar benda menjadi setimbang adalah:

1. Jumlah vector semua gaya eksternal yang bekerja pada benda harus nol.

2. Jumlah vector semua torsi eksternal yang bekerja pada benda diukur disekitar titik yang mungkin harus nol (titik kesetimbangan).

Karena manusia termasuk kategori benda tegar, benda tegar adalah benda yang tidak mengalami perubahan bentuk bila gaya dikerjakan pada benda tersebut. Benda tegar akan melakukan gerak translasi apabila gaya yang diberikan pada benda tepat mengenai suatu titik yang disebut titik berat. Titik berat merupakan titik dimana benda akan berada dalam keseimbangan rotasi( tidak mengalami rotasi) (Giancoli, 2001).

Menurut Davidovits (2008:2), Pusat gravitasi (c) orang tegak dengan lengan di sisinya adalah sekitar 56\% tinggi badan seseorang yang diukur dari 
telapak kaki. Berdasarkan paparan tersbut, pusat gravitasi yang menjadi titik kesetimbangan tubuh manusia dalam posisi tegak kira-kira $56 \%$ dari tinggi orang tersebut dan diukur dari telapak kaki, sehingga posisinya berada di sekitar pusar.

Dengan menggunakan syarat kesetimbangan torka, kita dapat menghitung gaya reaksi F. Misalkan massa orang itu adalah $\mathrm{m}$, jarak antara telapak kaki sampai pusat berat adalah L1, jarak antara telapak kaki sampai telapak tangan adalah L2.

\section{BAHAN DAN METODE}

Penelitian ini merupakan penelitian eksperimen, adapun alat dan bahan yang digunakan pada penelitian ini adalah sebagai berikut.
Alat dan Bahan
a.Alvaboard
b. Karton
c. Lem Tembak
d.Cutter
e.Pipa U Kabel Listrik
f. Neraca Pegas
g. Statif
h. Baut
i. Engsel Jendela 9 inchi
j. Beban 3 buah

\section{Prosedur}

\section{Prosedur Pembuatan Alat}

a. Menyiapkan alat dan bahan yang dibutuhkan.

b. Memotong pipa $U$ kabel listrik dengan panjang $75 \mathrm{~cm}$ sebagai poros utama alat simulasi push up.

c. Memasang engsel jendela sebagai tangan dibagian kanan dan kiri $13 \mathrm{~cm}$ dari atas menggunakan baut.

d. Membuat 2 buah kaki menggunakan karton. e. Memasang kaki $5 \mathrm{~cm}$ dari belakang menggunakan baut.

f. Memasang alas pada tangan dan kaki menggunakan alvaboard.

g. Jadilah alat biomekanika simulasi push up sebagai berikut.

\section{Prosedur Kerja}

a. Menyiapkan alat biomekanika simulasi push up

b. Mengaitkan neraca pegas bagian atas pada statif

c. Mengukur massa beban

d. Mengaitkan neraca pegas bagian bawah pada alat

e. Menetapkan jarak antara beban dan pengait neraca sebesar 20, 40 dan 60 $\mathrm{cm}$

f. Menetapkan panjang lengan sebesar $22 \mathrm{~cm}$

g. Mengukur gaya dalam keadaan standar sebelum diberi beban

h. Menetapkan lengan sudut sebesar $180^{\circ}$ atau dalam keadaan tegak lurus agar torsi dalam keadaan setimbang

i. Mengukur massa beban 1

j. Meletakkan beban pada lengan dengan jarak $20 \mathrm{~cm}$

k. Mengukur besar gaya serta besar sudutnya

1. Mengulangi dengan menggunakan variasi massa beban dan jarak lengan 40 dan $60 \mathrm{~cm}$

\section{HASIL DAN PEMBAHASAN}

Setelah merangkai alat simulasi push up, dilakukan pengambilan data dengan menggunakan berbagai variabel manipulasi yaitu massa dan panjang lengan badan. Pengambilan data dilakukan sebanyak 3 kali agar data yang didapat valid. Massa benda (m) yang digunakan bervariasi seperti pada tabel 1 . 
Panjang lengan badan (L) adalah pajang dari kepala sampai posisi massa pusat.

Tabel 1. Hasil Pengambilan Data

\begin{tabular}{|c|c|c|c|c|}
\hline No. & $\mathrm{m}(\mathrm{g})$ & $\mathrm{L}(\mathrm{cm})$ & $\mathrm{F}(\mathrm{N})$ & $\theta^{\circ}$ \\
\hline \multirow{9}{*}{1} & \multirow{9}{*}{125} & \multirow{3}{*}{20} & 2,1 & 120 \\
\hline & & & 2,2 & 115 \\
\hline & & & 2,2 & 115 \\
\hline & & \multirow{3}{*}{40} & 2,5 & 115 \\
\hline & & & 2,5 & 110 \\
\hline & & & 2,6 & 100 \\
\hline & & \multirow{3}{*}{60} & 2,9 & 110 \\
\hline & & & 2,9 & 95 \\
\hline & & & 3,0 & 95 \\
\hline \multirow{9}{*}{2} & \multirow{9}{*}{390} & \multirow{3}{*}{20} & 2,5 & 115 \\
\hline & & & 2,4 & 115 \\
\hline & & & 2,5 & 115 \\
\hline & & \multirow{3}{*}{40} & 3,6 & 100 \\
\hline & & & 3,6 & 100 \\
\hline & & & 3,6 & 105 \\
\hline & & \multirow{3}{*}{60} & 5,0 & 90 \\
\hline & & & 4,9 & 90 \\
\hline & & & 5,0 & 90 \\
\hline \multirow{9}{*}{3} & \multirow{9}{*}{515} & \multirow{3}{*}{20} & 3,1 & 100 \\
\hline & & & 3,0 & 105 \\
\hline & & & 3,0 & 105 \\
\hline & & \multirow{3}{*}{40} & 4,2 & 90 \\
\hline & & & 4,3 & 90 \\
\hline & & & 4,2 & 95 \\
\hline & & \multirow{3}{*}{60} & 5,0 & 85 \\
\hline & & & 5,2 & 90 \\
\hline & & & 5,1 & 90 \\
\hline
\end{tabular}

Tujuan pembuatan alat ini adalah untuk mengetahui pengaruh panjang lengan, massa, dan sudut terhadap besar gaya dan torsi. Berdasarkan grafik 1, pada massa $125 \mathrm{~g}$, gaya yang dihasilkan yang paling besar berada pada panjang badan $60 \mathrm{~cm}$ yaitu sebesar 2,9 N. Pada massa 290 g, gaya yang dihasilkan yang paling besar berada pada panjang badan $60 \mathrm{~cm}$ yaitu sebesar 5,0 N. Pada massa $515 \mathrm{~g}$, gaya yang dihasilkan yang paling besar berada pada panjang badan $60 \mathrm{~cm}$ yaitu sebesar 5,1 N. Berdasarkan data tersebut, semakin panjang jarak massa pusat maka semakin besar gaya yang dihasilkan dalam setiap massa yang berbeda.

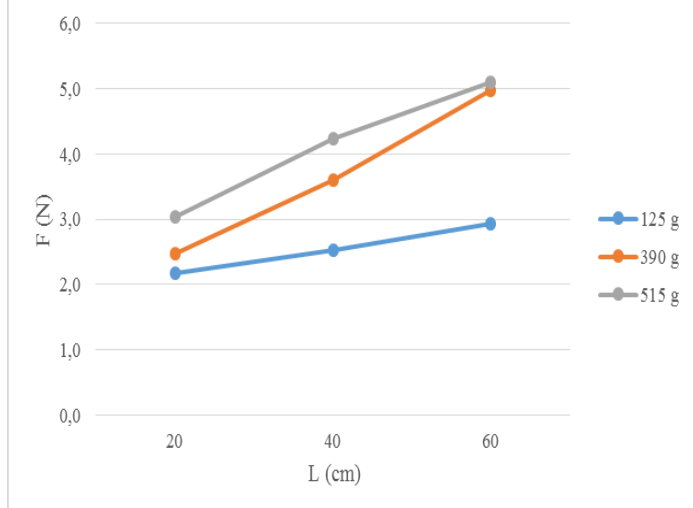

Grafik 1. Hubungan antara Gaya dan Panjang Lengan Badan

Selanjutnya, semakin besar massa pusat maka semakin besar pula gaya yang dihasilkan. Hal ini dapat dijelaskan bahwa semakin besar masssa badan maka gaya berat yang ditimbulkan juga akan semakin besar. Seperti ditegaskan pada hukum Newton yang ketiga yang berbunyi, "ketika dua benda berinteraksi, gaya pada kedua benda yang berasal dari satu sama lain selalu selalu sama magnitudonya dan berlawanan arah "(Halliday, 2005:109). Jadi ada dua benda yang berinteraksi disini, yaitu badan dan lantai yang arahnya berlawanan yang menimbulkan gaya yang selalu sama, sehingga semakin besar massa badan, semakin besar juga gaya berat yang ditimbulkan tetapi dalam arah yang berlawanan. Gaya yang berikan oleh badan terhadap lantai (ke bawah) dinamakan gaya aksi dan lantai juga akan menghasilkan gaya berlawanan (keatas) dengan besar yang sama yang dinamakan gaya reaksi.

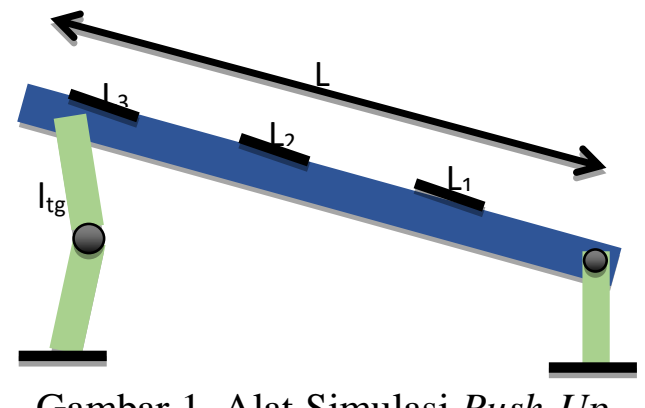

Gambar 1. Alat Simulasi Push-Up 
Dalam gerakan push-up berlaku juga kesetimbangan gaya dan torka. Manusia merupakan kategori benda tegar, suatu benda tegar akan melakukan gerak translasi apabila gaya yang diberikan pada benda tepat mengenai suatu titik yang disebut titik berat. Pada kesetimbangan torka memiliki salah satu ciri yaitu pusat gaya gravitasi dari suatu benda tegar merupakan titik kesetimbangan. Karena benda berada dalam kesetimbangan, total torsi terhadap titik apa pun juga nol. Untuk suatu benda yang berada dalam keseimbangan, baik jumlah gaya maupun jumlah torsi yang bekerja pada benda secara terpisah menjadi nol. Jika total torsi tidak nol, benda tidak seimbang dan akan berotasi dalam pengertian total torsi yang tidak nol beraksi padanya. Berdasarkan gambar 1, jika simulasi push up berada dalam keadaan standar dengan gaya $1 \mathrm{~N}$, sudut $180^{\circ}$, dan $\ell 22 \mathrm{~cm}$, sehingga torsi yang didapat $0 \mathrm{Nm}$.

Torsi yang dihitung pada simulasi push up ini adalah torsi total, yaitu selisih dari torsi lengan badan dan torsi lengan tangan. Persamaan yang digunakan adalah sebagai berikut.

$\tau_{\text {total }}=\tau_{1}-\tau_{2}$

$=w_{b} \cdot L-F \cdot \ell \operatorname{Sin} \theta$

$w_{b}$ adalah gaya berat yang didapat dari hasil perkalian gaya dan gravitasi. Pada massa $125 \mathrm{~g}$ didapat gaya berat sebesar $1,25 \mathrm{~N}$, gaya berat pada massa $290 \mathrm{~g}$ sebesar 2,9 $\mathrm{N}$ dan gaya berat pada massa $515 \mathrm{~g}$ sebesar 5,15. Setelah mengetahui gaya beratnya, torsi total dapat dihitung dan disajikan pada table 2 .

Tabel 2 Hasil Perhitungan Torsi

\begin{tabular}{|c|c|c|c|}
\hline \multirow{2}{*}{$\mathrm{L}(\mathrm{cm})$} & \multicolumn{3}{|c|}{ Torsi $(\mathrm{Nm})$} \\
\cline { 2 - 4 } & $125 \mathrm{~g}$ & $390 \mathrm{~g}$ & $515 \mathrm{~g}$ \\
\hline 20 & -0.18 & 0.26 & 0.38 \\
\hline 40 & -0.03 & 0.78 & 1.13 \\
\hline 60 & 0.12 & 1.25 & 1.97 \\
\hline
\end{tabular}

Kemudian disajikan menjadi grafik 2. Berdasarkan grafik tersebut, semakin besar panjang $\mathrm{L}$ maka semakin besar juga torsinya.

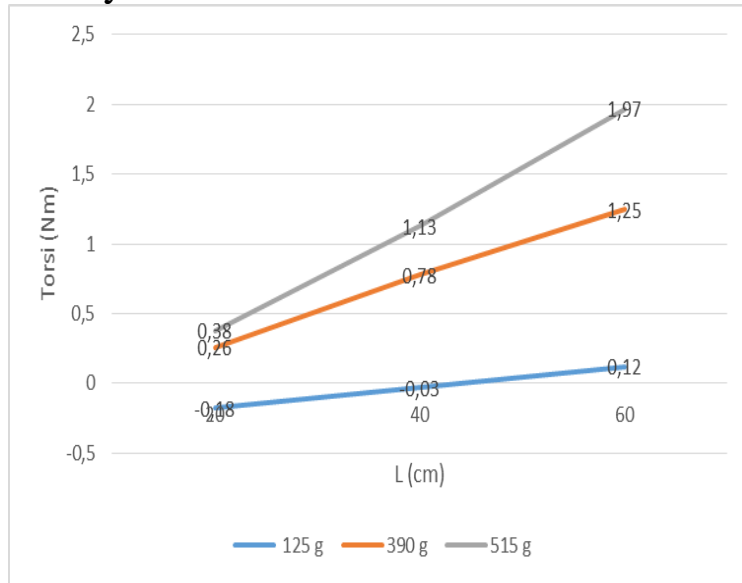

Grafik 2 Hubungan antara Torsi dengan Panjang Lengan Badan

Hasil penelitian memuat ringkasan data dari penelitian tanpa mendiskusikan implikasinya, ringkasan dalam bentuk yang paling informatif dapat diringkas dalam bentuk tabel/grafik/gambar dan harus dijelaskan dalam teks.

Substansi dari pembahasan dalam penelitian memuat intepretasi data hasil penelitian yang mengkaitkan dengan teori/hasil penelitian terdahulu serta pemahaman terhadap kondisi yang ada saat ini. Pada bagian ini penulis juga menjelaskan logika tentang penerimaan atau penolakan hipotesis serta menjelaskan mengapa hasil penelitian ini berbeda dengan hasil penelitian orang lain. Pembahasan ditulis melekat dengan data yang dibahas. Pembahasan diusahakan tidak terpisah dengan data yang dibahas.

\section{KESIMPULAN}

Berdasarkan hasil eksperimen bahwa semakin besar panjang lengan badan maka semakin besar pula gaya dan torsi. Semakin besar massa benda maka semakin besar pula gaya. 


\section{Ucapan Terima Kasih}

Penulis mengucapkan banyak terimakasih kepada rekan saya Andi Asmar Pendidikan Sains A 2017, bapak Heru Kuswanto selaku dosen pembimbing proyek ini dan semua pihak yang telah membantu dalam menyelesaikan proyek ini.

\section{DAFTAR PUSTAKA}

Contreras Bret, Schoenfeld Brad, Mike Jonathan, Tiryaki-Sonmez Gul, Cronin John, and Vaino Elsbeth,. The Biomechanics of the Pushup: Implications for Resistance Training Programs. Journal of Strength and Conditioning Research 34(5): 41-46, 2012

Davidovits Paul. 2008. Physics in Biology and Medicine. United Kingdom : Academic Press Elsevier.

Payton J. Carl and Bartlett J., Roger, Biomechanical Evaluation of Movement in Sport and Exercise (London and New York: Routledge Taylor \& Francis Group, 2008)

Giancoli C. Douglas. 2001. Fisika. Jakarta : Erlangga.

Halliday, David. 2005. Fisika Dasar Jilid 1. Jakarta : Erlangga.

Hewitt G. Paul. Conceptual Integrated Science. USA: Pearson Education 2007.

Suprak N. David, Dawees Jay, And Stephenson D. Mark. The Effect Of Position On The Percentage Of Body Mass Supported During Traditional And Modified PushUp Variants. Journal of Strength and Conditioning Research 25(2) : 497-503, 2011.

USAID Prioritizing Reform, Innovation, and Opportunities for Reaching Indonesia's Teachers, Administrators, and Students (USAID PRIORITAS). Training Module IV - Good Practices in The Junior Secondary School: Teaching Science. RTI International is a registered trademark and a trade name of Research Triangle Institute 2017.

Yudas W. James, Budach D. Brian, Ellerbusch V. Jay, Stucky M. Mcraig, Wait R. Kevin, and Hollman H. John. Comparison Of Muscle-Activation Patterns During The Conventional PushUp And Perfect Pushup ${ }^{\mathrm{TM}}$ Exercises. Journal of Strength and Conditioning Research 24(12): 3352-3362, 2010. 